NASA Technical Memorandum 105839

\title{
Overview of High Performance Aircraft Propulsion Research
}

Thomas J. Biesiadny

Lewis Research Center

Cleveland, Ohio

Prepared for the

Aerotech '92 Conference

Anaheim, California, October 5-8, 1992 


\title{
Overview of High Performance Aircraft Propulsion Research
}

\author{
Thomas J. Biesiadny \\ National Aeronautics and Space Administration \\ Lewis Research Center \\ Cleveland, $\mathrm{OH} 44135$
}

\begin{abstract}
This paper presents the overall scope of the NASA Lewis High Performance Aircraft Propulsion Research Program. High performance fighter aircraft of interest include supersonic fighters with such capabilities as short takeoff and vertical landing (STOVL) and/or high maneuverability. The NASA Lewis effort involving STOVL propulsion systems is focused primarily on component-level experimental and analytical research. The highmaneuverability portion of this effort, called the High Alpha Technology Program (HATP), is part of a cooperative program among NASA's Lewis, Langley, Ames, and Dryden facilities. The overall objective of the NASA Inlet Experiments portion of the HATP, which NASA Lewis leads, is to develop and enhance inlet technology that will ensure high performance and stability of the propulsion system during aircraft maneuvers at high angles of attack. To accomplish this objective, both wind-tunnel and flight experiments are used to obtain steady-state and dynamic data, and computational fluid dynamics (CFD) codes are used for analyses. This overview of the High Performance Aircraft Propulsion Research Program includes a sampling of the results obtained thus far and plans for the future.
\end{abstract}

\section{Introduction}

The NASA Lewis High Performance Aircraft Propulsion Research Program is concentrated on short takeoff and vertical landing (STOVL) and high maneuverability capabilities. A supersonic STOVL aircraft concept would offer enhanced mission capability, operational flexibility, survivability, and utility over conventional replacement aircraft. The work at Lewis on STOVL propulsion systems is focused primarily on component-level experimental and analytical research. This research is expected to provide data bases for verification of design technology and for calibration of the CFD tools available for design use. Descriptions of key technologies and results of research efforts involving integrated controls, hot gas ingestion, offtake systems, and exhaust systems will be presented.

The high-maneuverability portion of this effort, called the High Alpha Technology Program (HATP), is part of a cooperative program among the NASA's Lewis, Langley, Ames, and Dryden facilities. The key technology challenge is to achieve effective control of supersonic aircraft at low subsonic speeds and high angles of attack above $60^{\circ}$, thus extending the flight regime into the high-altitude, lowMach-number portion of the flight envelope.

The overall objective of the NASA Inlet Experiments portion of the HATP, which NASA Lewis leads, is to develop and enhance inlet technology that will ensure high performance and stability of the propulsion system during aircraft maneuvers at high angles of attack. The challenge is to design an inlet to deliver sufficiently low total pressure distortion and minimum swirl to the engine so it does not stall. At the same time, adequate inlet recovery (i.e., thrust) must be maintained so that in post wing-stall conditions the aircraft is still maneuverable.

The approach for accomplishing this objective involves both wind-tunnel and flight experiments to obtain steady-state and dynamics data and analyses using CFD codes. This overview of the High Performance Aircraft Propulsion effort includes a sampling of the results obtained thus far and plans for the future.

\section{STOVL Aircraft Propulsion}

\section{Background}

After the turn of the century, the military is likely to need replacement fighter/attack aircraft. Aircraft with short takeoff and vertical landing capabilities would offer enhanced operational flexibility. Significant work has been done to identify and resolve critical technology issues in the military area.

The highly successful AV-8B Advanced Harrier, a subsonic STOVL aircraft, has been operational for a number of years with the United States Marines and the United Kingdom services. The U.S. Navy and Marines are likely to replace this aircraft, as well as other highperformance fighter/attack aircraft such as the F/A-18, after the turn of the century, when the aircraft reach the ends of their service lives. In this light, a supersonic STOVL aircraft would offer enhanced mission capability, operational flexibility, survivability, and utility over conventional replacement aircraft.

Many innovative vertical and short takeoff and landing (V/STOL) aircraft configurations have been proposed and some built, particularly during the 1970's, but none have 
resulted in production aircraft. Because of these abortive attempts, a flight demonstrator would be necessary for the successful introduction of a supersonic STOVL aircraft by convincingly demonstrating supersonic as well as STOVL capability in a single-engine aircraft. Cost, however, could be expected to be a major program driver. Given the reality of shrinking Department of Defense (DOD) budgets, this single-engine propulsion system probably would have to be a derivative of an existing or off-the-shelf engine to keep the demonstrator cost down.

Although a specific propulsion concept has not been selected and specific military requirements for the aircraft have not been identified, propulsion system technology levels have advanced to the stage that a supersonic STOVL system appears feasible. Even so, several areas require consideration before a supersonic STOVL aircraft and propulsion system can be considered for operational status. If a STOVL flight demonstrator is to be available in the late 1990's, the technologies that could impact this type aircraft should be identified.

In recent years, NASA has been heavily involved in the U.S. supersonic STOVL effort, working with research organizations of the U.S. Navy and Air Force (although the Air Force has discontinued its supersonic STOVL study activities). However, recent budget cuts have adversely affected the scope of the NASA program. Any future NASA program will depend on greater DOD involvement or support. NASA's program, which is coordinated among the Lewis, Ames, and Langley Research Centers, has featured design studies, computational fluid dynamics (CFD) work, small- and large-scale wind-tunnel tests, ground environment experiments, simulation activities, and flight experiments. Current efforts include studies, smallscale tests, and integrated flight-propulsion controls programs.

As part of the STOVL effort, the United States and the United Kingdom entered into a joint program in the mid-1980's. Under this program, studies were conducted by engine and airframe manufacturers in both countries. Figure 1 shows the aircraft studied in the U.S. effort. The propulsion system concepts for these configurations included:

(a) Ejector Augmentor, in which engine air is used to drive an ejector forward of the aircraft center of gravity (c.g.) for hover

(b) Remote Augmented Lift System, which is similar to the Ejector Augmentor concept except that a burner and nozzle are used for vertical lift

(c) Mixed Flow Vectored Thrust, in which exhaust gas from a mixed flow bypass engine is used for vertical lift (d) Hybrid Tandem Fan, which uses a variable-cycle engine with fan stages separated.

Although there are others, these four single-engine concepts were believed to represent the best alternatives at the time of the studies. These studies did not result in a preference for a specific airframe/propulsion concept, but they eliminated from further consideration the Hybrid Tandem Fan (heavy and complex) and, potentially, the Remote Augmented Lift System (hot footprint from the burner). The studies did, however, narrow the large variety of possible propulsion system combinations to those that use

(a) for wing-borne flight, a mixed flow turbofan engine whose exhaust is through a single rear nozzle; and

(b) for jet-borne flight, a vertical lift system separate from the engine.

Although a preferred propulsion system was not identified, the U.S./U.K. teams recognized critical technologies that will enable STOVL to be an attractive option for the next generation of fighter/attack aircraft systems. For the propulsion system, critical technologies include high-performance and low-loss exhaust gas offtakes and ducts that deliver the flow to the vertical thrusting systems, hot gas ingestion alleviation and avoidance techniques or hardware, integrated controls, vertical lift nozzles, and STOVL augmentors. For the aircraft, critical technologies include control quality, handling quality, and airframe operation near the ground. Progress continues in these basic research areas, but there is much to be done, and resources are limited. Still, the propulsion system is the key factor in any STOVL concept.

The objective of the NASA-Lewis STOVL aircraft propulsion program is to provide data bases for verification of design technology and for calibration of CFD tools available for design use.

The studies have identified critical technology needs for future supersonic STOVL aircraft. The elements in which Lewis is involved are integrated flight-propulsion controls, hot gas ingestion, exhaust gas offtakes and ducts, vertical lift nozzles, and STOVL augmentors. The approach is to conduct component-level experimental and analytical research in each of these elements. These efforts will be described more fully.

\section{Integrated Flight-Propulsion Controls}

Integrated controls concepts and designs are required for supersonic STOVL because of the complexity of controlling this type of aircraft, particularly in low-speed flight 
and hover. In these flight regimes, the aircraft depends on the propulsion system for lift in addition to flight path and attitude control. Therefore, the propulsion system must be able to provide aircraft control in this flight regime while retaining sufficient power to maintain flight.

The NASA Lewis and NASA Ames Research Centers are involved in a program that has as its goal a fixed-base simulation of an Integrated Flight-Propulsion Control concept based on the Air Force Design Methods for Integrated Control Systems (DMICS) design approach (fig. 2). Independently, Lewis is pursuing another design approach called Integrated Methodology for Propulsion and Aircraft Control (IMPAC). The goal of these methodologies is a validated design procedure for integrated control which performs a systematic, top-down design based on the mission requirements and the system to be integrated. For supersonic STOVL, the control concepts must be defined, design methods explored, and flying qualities criteria defined. Then, these concepts and criteria must be investigated in ground-based tests and flight experiments. NASA Lewis will apply the control methodologies, simulate the resulting control logic in software, and evaluate the control logic on nonpiloted and piloted simulations, the latter jointly with NASA Ames. The DMICS approach is currently scheduled for piloted evaluation on the Ames fixed base and vertical motion simulators. The IMPAC approach is targeted for a forward flight-to-hover transition simulation in the near future.

\section{Hot Gas Ingestion and Ground Environment}

One of the critical problems associated with the vertical lift concept is that of hot gas ingestion while the aircraft is near the ground-as in the takeoff, hover, and landing modes. This phenomenon occurs when hot exhaust gas from the engine impinges on the ground and is transported forward so that a portion of this gas is ingested by the engine inlet (fig. 3). Once this occurs, the hot gas can significantly affect engine stability and performance and, therefore, aircraft control and safety.

In an ongoing NASA Lewis hot gas ingestion program, ground effects were studied at the engine inlet for a 9.2-percent scale STOVL model in the Lewis 9x15 LowSpeed Wind Tunnel. The facility has a sheet laser illumination system to document complex flows associated with hot gas ingestion (fig. 4). Data were obtained at simulated exhaust gas temperatures to $540{ }^{\circ} \mathrm{C}$, and an extensive airflow visualization data base was produced. These data pertain to near-field and structural acoustics, the effectiveness of Lift Improvement Devices (LIDS), thermal footprint and temperature distribution on the undersurface of the model, and propulsion system inlet distortion levels.

A follow-on phase to this program is planned for fiscal year 1993. A modular advanced STOVL concept model (10.34-percent scale) is being designed and fabricated. The configuration will simulate the exhaust of

(a) a lift fan of a Shaft Driven Lift Fan (SDLF) concept in which a dual function, or convertible, engine produces shaft horsepower to drive the lift fan plus provide thrust for forward flight;

(b) a lift engine of a Lift Plus Lift Cruise (LPLC) concept in which one engine is dedicated to vertical lift and another engine provides both lift and cruise thrust; and

(c) lift nozzles of a Mixed Flow Vectored Thrust (MFVT) concept in which exhaust gas from a mixed flow bypass engine is used for vertical lift.

Data to be obtained include those taken with the 9.2-percent model plus jet-plume flow fields using a Laser Doppler Velocimeter (LDV) and static jet-induced interactions.

As a result of the test program, we are developing an extensive data base for an in-depth understanding of hot gas ingestion. The data will be used to improve hot gas ingestion empirical prediction techniques for screening future STOVL aircraft concepts during the preliminary design phase as well as to evaluate ongoing computational prediction methods.

\section{Offtakes and Ducts}

Offtakes and ducts are other areas being investigated. In some of the STOVL concepts that have been studied, air from the engine must be brought forward through devices such as offtakes, valves, and ducts to vertical lift devices forward of the engine.

A generic one-third scale model of a tailpipe offtake system was tested at Lewis (figs. 5 and 6). The model consisted of a tailpipe with elbows, ducts, and flow control nozzles, a blind flange to simulate a blocked cruise nozzle, and a small ventral nozzle. The flow split was 45 percent to each offtake and 10 percent to the ventral nozzle. The main objective was to obtain experimental data for comparison with internal flow pattern and performance predictions from a CFD analysis. Performance tests were made with ambient air at tailpipe-to-ambient pressure ratios from approximately 2 to 5 at a tailpipe Mach Number of 0.3 . The initial comparisons between the experimental data and those produced by the CFD code revealed some shortcomings in the CFD code calculations. The cause of these differences will be investigated further through an adjustment of the boundary conditions and grid used with the CFD code.

Since the test hardware is modular, additional research with variations of the configuration shown in figure 5 was 
quite easy. The modified configurations are shown in figure 7. Tests included configurations with the offtakes

(a) located far enough downstream of the turbine exit that flows are relatively mixed and uniform (fig. 5);

(b) near the turbine exit in a mixed flow, low bypass ratio configuration (fig. $7(a)$ );

(c) with rounded edges at the upstream edge of the offtake elbows (fig. 7(b)); and

(d) with a blocker, both flat and shaped, just downstream of the offtakes (figs. 7(c) and (d)).

The general objective for this testing was to investigate trends in offtake pressure loss and total pressure distribution for configuration features expected to affect performance. The tailpipe Mach number was varied from 0.2 to 0.4 . Data from tests with these configurations are in the process of being analyzed.

Hardware was designed and fabrication was started for a mixed-flow tailpipe and offtake system to study generic valve and ducting configurations (fig. 8), but the effort was terminated because of funding constraints. The intent here was to gather pressure loss and heat transfer data at temperatures up to $540{ }^{\circ} \mathrm{C}$ for a system that simulated flow from a mixed flow turbofan engine. These data would have been used to assist in the design of high-performance, low-loss, exhaust-gas offtakes and ducts.

\section{Vertical Lift Systems}

NASA is also investigating design criteria and developing a technology base for vertical lift thrust nozzles such as ventral nozzles used for pitch and trim control. One major objective of this effort is to establish aerodynamic design principles and a data base for vertical lift components through experimental testing and CFD analyses. A full Navier-Stokes CFD code, PARC3D, is being used to predict the internal flow patterns and overall ventral system performance for selected configurations.

For the baseline configuration (fig. 9), the PARC3D code did an excellent job of analytically predicting internal flow patterns and system performance. The solution produced detailed flow patterns and predicted performance parameters, such as thrust and flow coefficients, within 1 percent of the measured values. As a result, this CFD analytical tool is considered calibrated for use in the analysis of STOVL propulsion ventral nozzle designs.

In addition to the baseline configuration, an annular tailpipe flow path and an annular tailpipe flow path with a tailpipe blocker immediately downstream of the ventral duct were investigated. The annular flow tailpipe simulated the bypass flow of a turbofan engine being drawn into the ventral duct (this has been referred to as a separate flow system). A ventral duct length shorter than the baseline length was also investigated. To examine the flow fields during the transition from hover to wing-borne flight, a configuration with the ventral nozzle and the axial nozzle flowing was investigated.

To facilitate transition, vectoring capability is desired in ventral nozzles. One possible method to provide thrust vectoring would be to implement a clam-shell type twodimensional converging nozzle. The previously described ventral nozzle experiment was modified to incorporate this technique (fig. 10). Although in a production design each of the outer shells could be independently actuated, for this experiment the exit area and the two outer shells were connected. The shells, however, could be manually rotated $20^{\circ}$ fore and aft from the vertical. Results of this experiment are shown in figure 11. Of significance are the data showing the sensitivity of this configuration to severe flow angles that could be associated with STOVL applications. Here, rounding the leading edge to the ventral nozzle duct resulted in a significant improvement in nozzle performance.

Vane-type ventral nozzles have been tested. The objective with these nozzles was to obtain performance characteristics. These included nozzle flow, thrust, and vectoring up to $45^{\circ}$, plume total pressure profiles, pumping capability for engine compartment cooling, and vectoring forces near maximum lift. Figure 12 shows the basic design. Vanes were also added to the swivel nozzle for yaw control (fig. 13).

\section{STOVL Augmentors}

We have completed experimental research with ejector augmentors. In the last program, a Boeing/deHavilland cooperative effort provided an ejector designed for the elevated primary gas temperature expected in a mixed flow turbofan engine (fig. 14). The U.S./U.K. ASTOVL studies indicated the value of such systems, and therefore the interest in a hot primary ejector was continued. Our conclusions about ejector type STOVL thrust augmentors are that, although they have been successfully demonstrated and the desired performance levels have been achieved, designing them remains an art. Figure 15, a selected result from the ejector experimental research, shows a correlation of thrust augmentation ratio with a nondimensional flow parameter. This correlation minimizes temperature dependence. If this were to hold true for other ejector models, it suggests that cold flow tests can be used to predict hot flow results more quickly and at a lower cost. Even though we have completed our currently planned research on thrust augmenting ejector systems for supersonic STOVL, more work could be done. Specifically, ejector designs with primary nozzle pressure ratios representative 
of future advanced military engines need to be investigated, but this is not currently perceived as a high priority need.

\section{Future Work}

The future for STOVL-related work at Lewis is in part dependent on the direction taken by the U.S. Navy and the Defense Advanced Research Projects Agency (DARPA). They have shown some interest in technology validation experiments directed toward selection of a powered lift concept for a STOVL Strike Fighter (SSF).

\section{High Maneuverability Propulsion Research}

\section{Background}

High Maneuverability Propulsion Research is directed at expanding the flight envelope of high performance aircraft. The overall objective of the inlet experiments program is to develop and enhance inlet technology that will ensure high performance and stability of the propulsion system during aircraft maneuvers at high angles of attack.

The flight regime being investigated represents an especially challenging problem for supersonic inlets because of the severe adverse effect sharp lips have on recovery and distortion at these conditions. This results in reduced thrust and stability of the propulsion system. Other propulsion system/airframe integration programs have provided an experimental data base applicable to maneuverable supersonic aircraft, but not at low-subsonic-speed/highangle-of-attack conditions.

Several different types of distortions must be considered in the design of these inlets. One type, total pressure distortion, is the most commonly encountered distortion and has received the greatest attention to date. It can result when the inlet is at high angle-of-attack and/or angle-ofsideslip conditions. Total pressure distortion of a quasisteady type can result from a yaw rate maneuver at high angles of attack.

Another type of distortion is caused by swirl (vortices with an axial velocity component), such as when an inlet ingests a vortex shed from the aircraft during maneuvers. Swirl can also be encountered when an inlet is attached to an S-shaped (offset) duct, and is due to secondary flow generation in the duct.

Any of these types of distortion will adversely affect engine stability. Severe distortion of any one type can cause engine stall. Combining several types of moderated distortion can also cause engine stall.

The HATP utilizes the F-18 High Alpha Research Vehicle (HARV) for full scale validation of the technologies associated with high angle-of-attack aerodynamics and post wing stall control. The HARV is an ideal vehicle because of its high angle-of-attack capability and stable propulsion system characteristics. During the Navy envelope expansion program, the F-18 aircraft experienced some instances of thrust loss, flameout and/or engine stall when performing dynamic maneuvers outside the normal flight envelope. This might be a propulsion system/ airframe integration problem caused by high angle-of-attack and yaw rates rather than steady state high angle of attack and yaw, or it could be a propulsion-related problem. To investigate the cause of these anomalies, NASA obtained the HARV from the Navy, where it was used as the unique high alpha test aircraft during the F-18 development program.

The approach for accomplishing the High Alpha Inlet Experiments effort involves both flight and wind-tunnel experiments, in which steady state and dynamics data will be obtained, and CFD analyses.

\section{Experiments}

The experimental part of the program consists of expanding the data base to increase inlet angle-of-attack capability and to determine the effect of ingesting vortices on engine stall. The prior experiments to increase inlet angle-of-attack capability considered only isolated inlets; the effect of a forebody on inlet performance was not investigated. The HARV represents an excellent aircraft on which to focus research interest because of its well defined inlet/forebody configuration and its high angle-of-attack capability. Therefore, experiments will be conducted on the HARV as well as on subscale, and possibly full-scale, F-18 models to expand the data base.

Both diagnostic and research flights are planned at Dryden as part of the Inlet Experiments Program. The diagnostic flights will attempt to determine whether the loss of thrust, flameout, and engine stall previously encountered in Navy F-18 aircraft envelope expansion flights were due to inlet-related phenomena or a fuel system anomaly. The research flights are intended to gather detailed information inside, as well as outside, the inlet duct.

The research portion of the flight program will acquire steady state and dynamic data to investigate inlet-related problems suggested from diagnostic flights or occurring during research flights, investigate scale effects, generate a data base for CFD code evaluation, and investigate effects of the method used to pump air through the inlet during subscale model tests.

Steady state tests were conducted in the Ames National Full-Scale Aerodynamic Complex (NFAC) using a full-scale F-18 aircraft model but with engines removed. This is a flow-through model with a maximum design corrected airflow of 85 percent. A study has been completed which determined what is required to increased the airflow to 100 percent. The instrumentation for this 
phase of the program, if it is done, will be a subset of that planned for the 20-percent scale model tests. Currently, the lack of funding prevents this from being accomplished.

Steady state tests are planned in the Lewis $9 \times 15$ LowSpeed Wind Tunnel (LSWT) using a 20-percent model of the F-18 HARV (figs. 16 and 17) to investigate effects on inlet performance of the aircraft forebody and the effect of scale. The model will also be used to investigate the effect of inlet pumping on inlet performance, using either a vacuum or simulator fans, and forebody with and without faired over inlets. Furthermore, a data base will be generated for CFD code calibration. Comparisons will be made with flight results from the HARV. A test matrix is shown in figure 18.

\section{Computational Fluid Dynamies}

The computational part of the Inlet Experiments Program consists of applying and evaluating computational tools. This will be concerned solely with steady state conditions since the codes have not matured to the point where they can be used for dynamic data. Internal flow codes will be evaluated using data from the expanded data base. These internal codes will then be combined with external flow codes, which are necessary to model the flow over the forebody to determine the flow field at the inlet entrance. These combined codes will then be evaluated, also with the use of data from the expanded data base.

Four facilities will be involved in the CFD effort in one way or another. Langley is using the CFL3D code and Ames the F3D code to model the external aerodynamics of the F-18 HARV with faired over inlets. Lewis is working with both these centers as the output of their codes will provide input to the Lewis codes, PARC3D and PEPSIG, which are dedicated to flow in the inlet duct. Dryden will provide the data from the HARV flights to be used for evaluation of these codes.

\section{Concluding Remarks}

An overview of the NASA Lewis High Performance Propulsion effort has been presented. The opportunities for STOVL aircraft have been identified, and the critical technologies defined. Whether these aircraft systems will flourish remains to be seen. On the other hand, the HATP is a multi-center NASA program that is just reaching the point where experimental data is being gathered. It appears to have a solid future. 


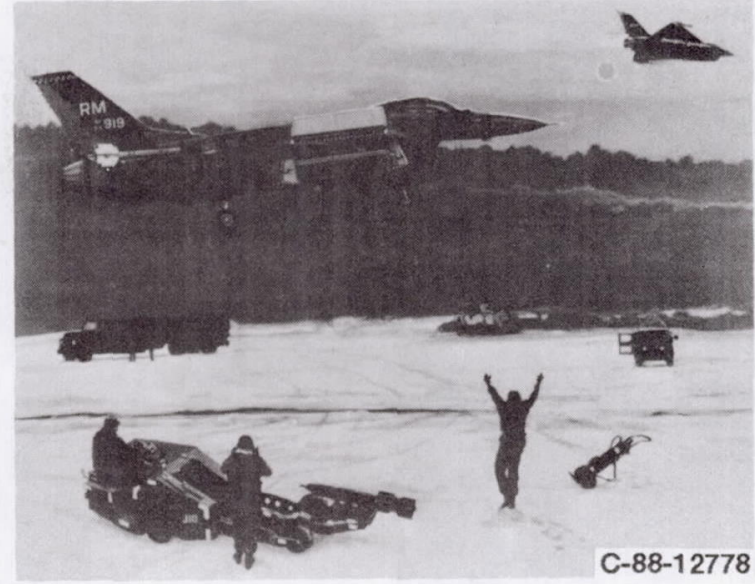

(a) Ejector augmentor.

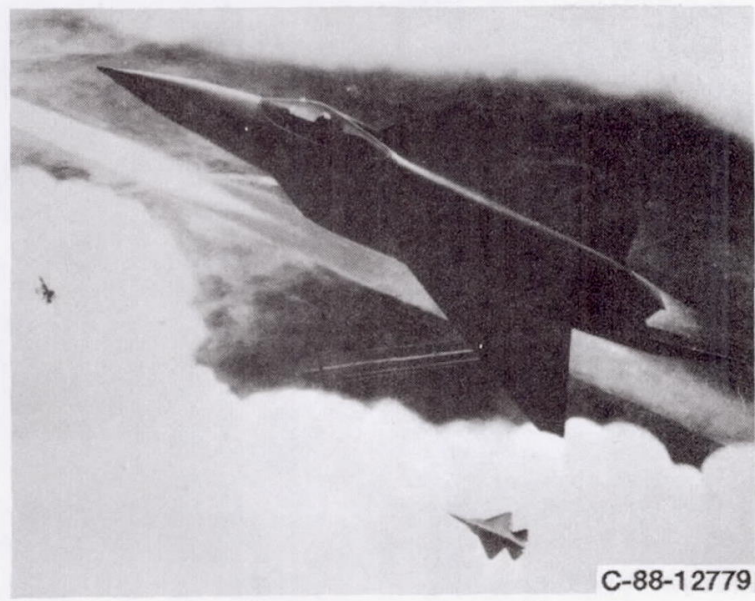

(c) Mixed flow vectored thrust.

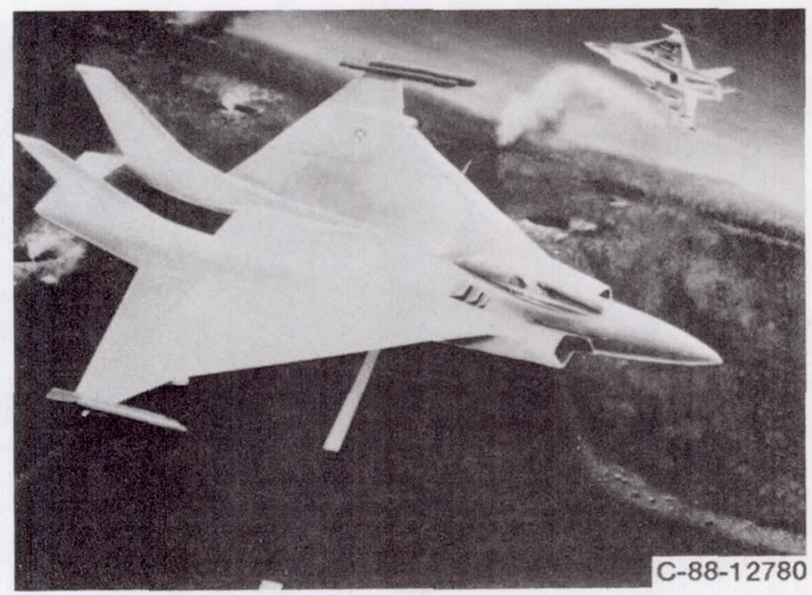

(b) Remote augmented lift system.

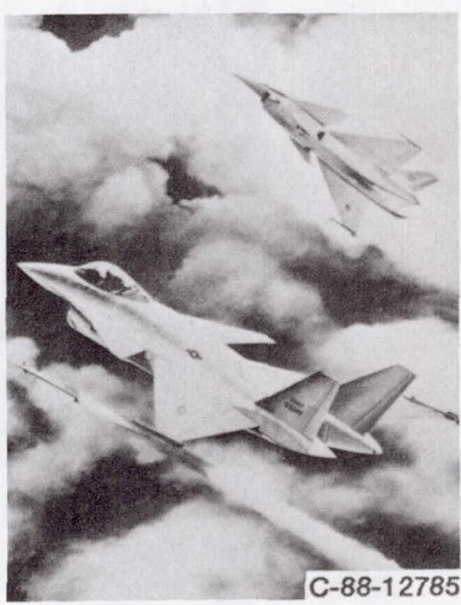

(d)Hybrid tandem fan.

Figure 1.-U.S./U.K. ASTOVL study configurations.

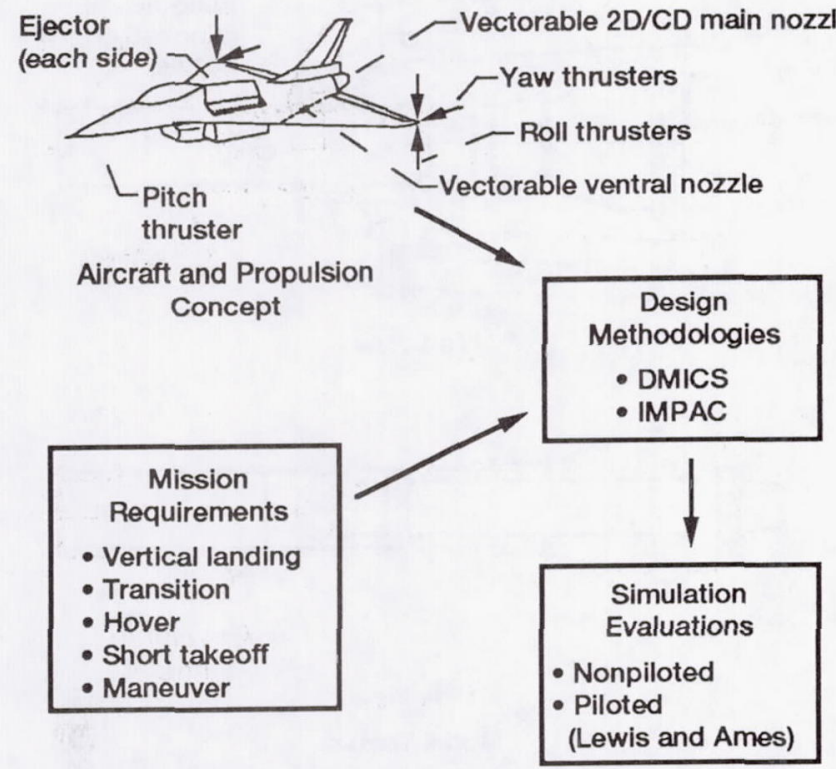

Figure 2.-Integrated flight-propulsion controls approach.

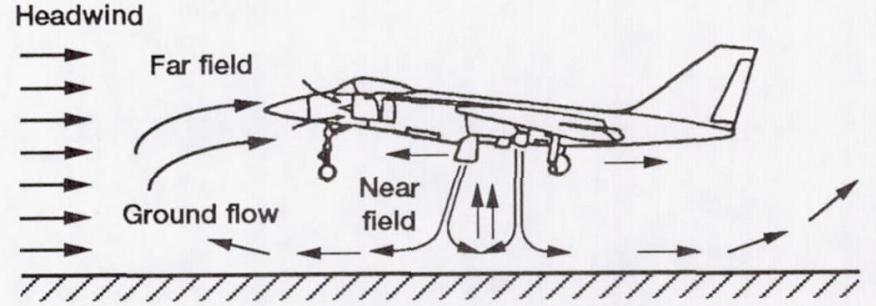

Figure 3.-Hot-gas ingestion phenomena. 


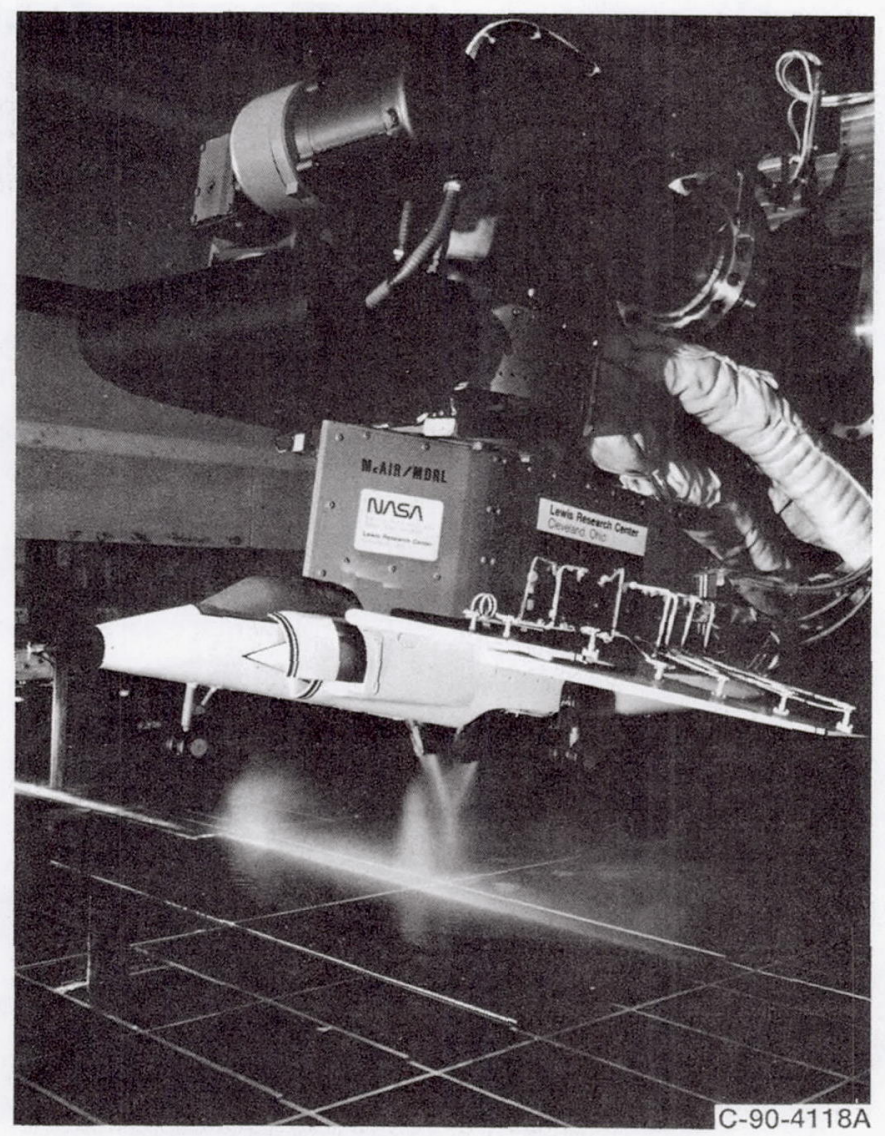

Figure 4.-Sheet laser illumination of complex flows associated with hot gas ingestion.

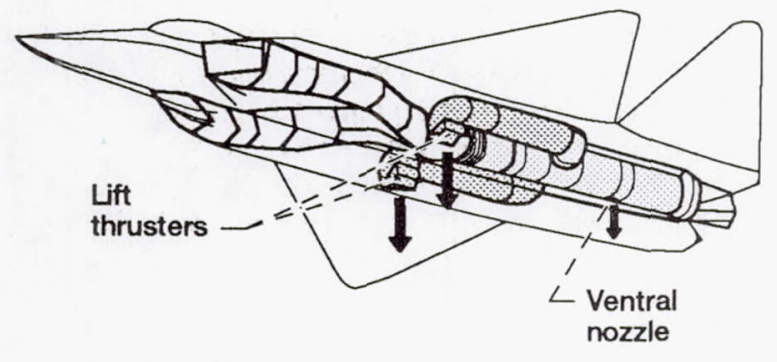

Aircraft
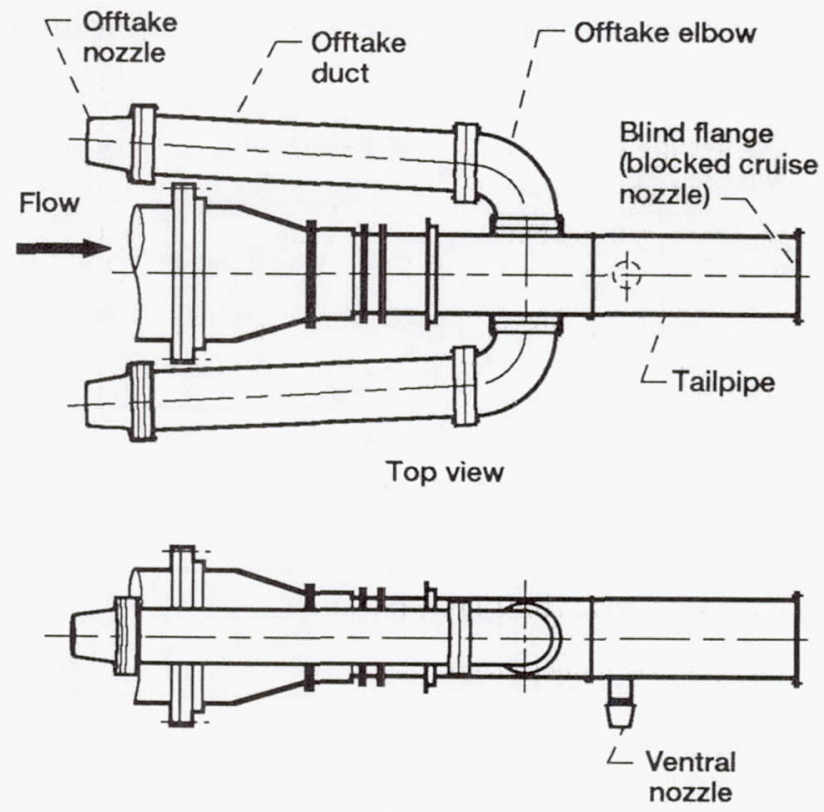

Side view

Model Tested

Figure 5.-Tailpipe offtake experimental model schematic. 


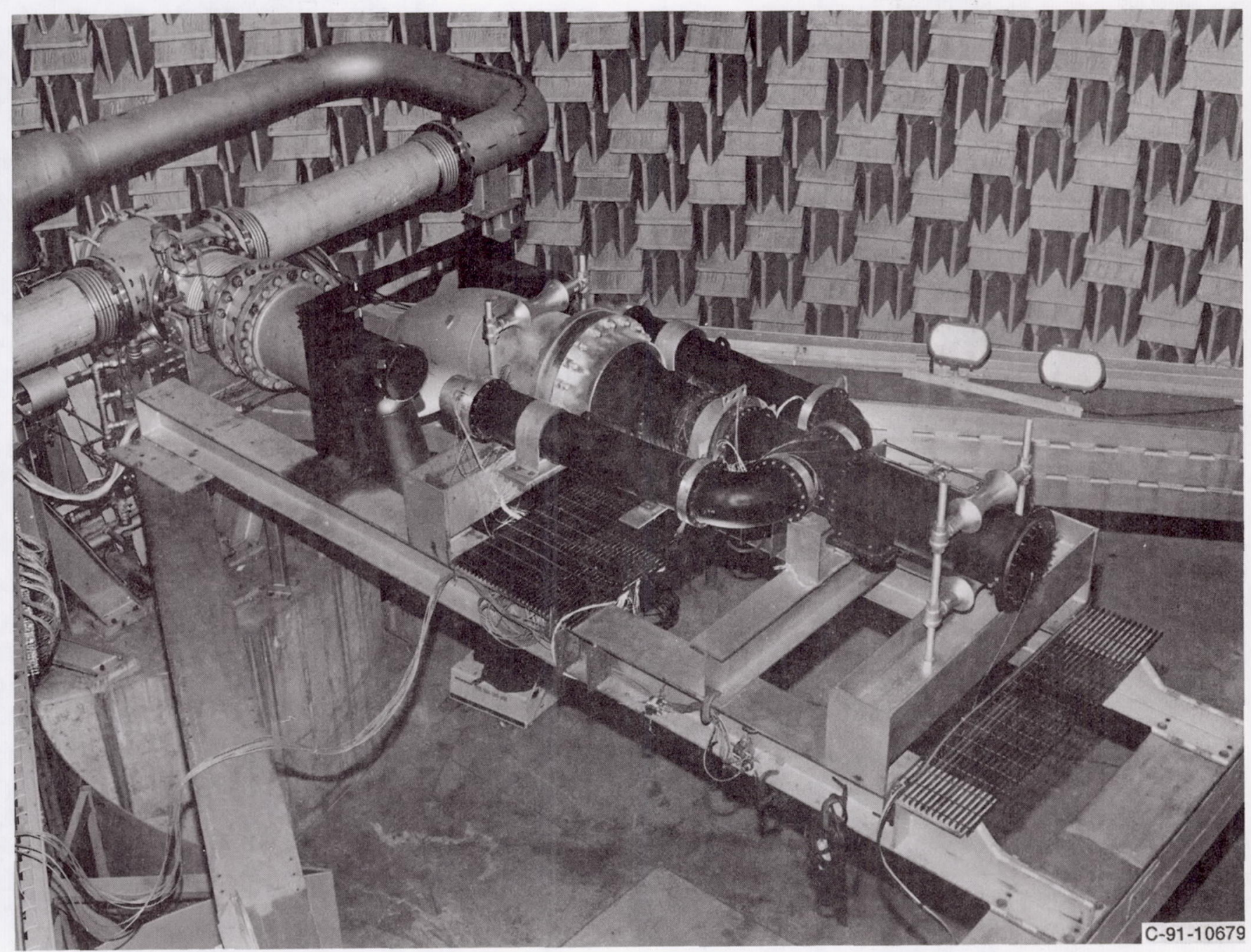

Figure 6.-Tailpipe-offtake experimental hardware. 


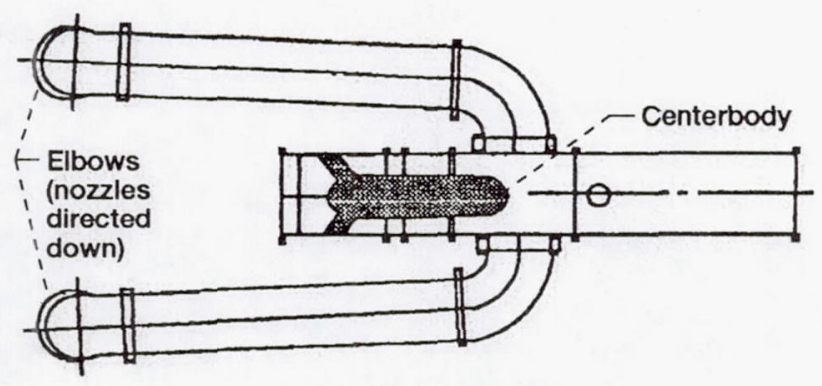

(a) Tailpipe with centerbody.

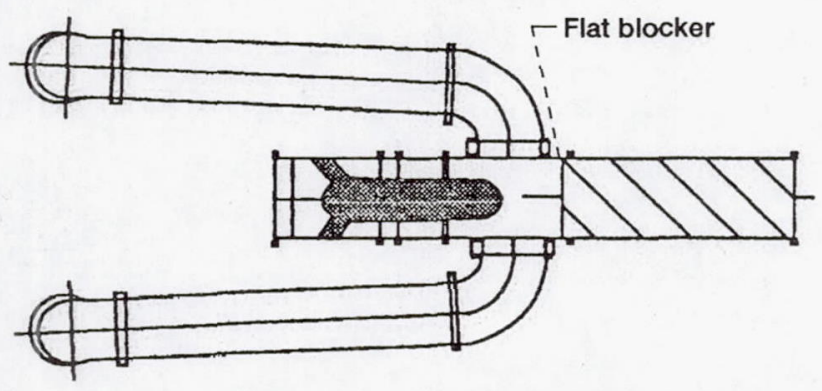

(c) Flat blocker near offtakes.

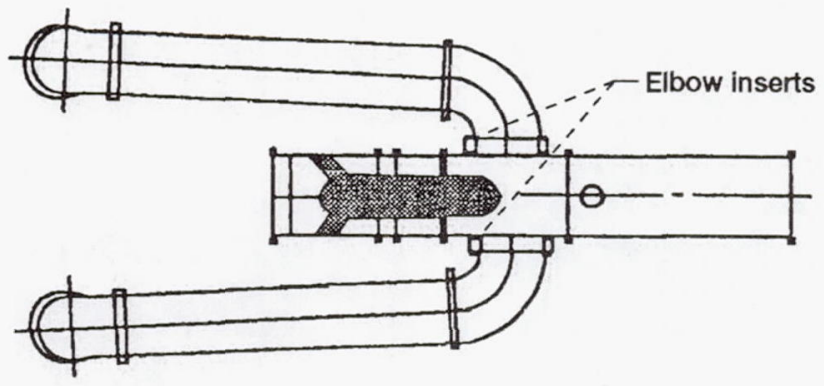

(b) Rounded edge at offtake

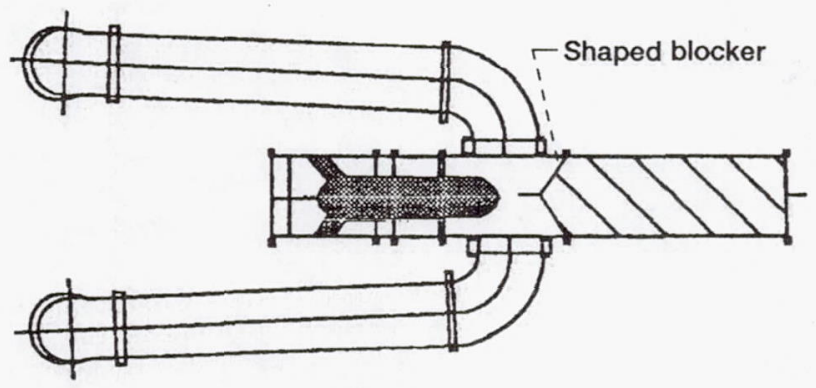

(d) Shaped blocker near offtakes.

Figure 7.-Schematics of offtake systems tested.

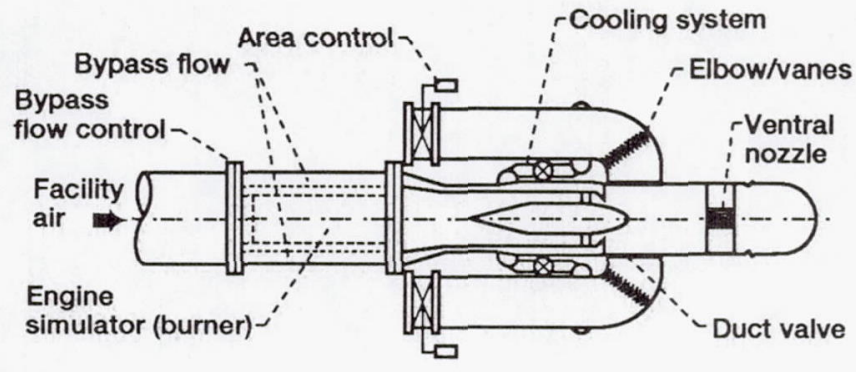

Variables

- Engine bypass ratio - Flow offtake configuration

- Cooling flows

- Duct/turning vane configuration

- Ventral nozzle size/location
Typical Results

- Heat transfer data for cooling system design

- Flow pressure/temperature profiles

- Fan and core stream mixing

- Effect of nonsymmetric lift nozzle area variation

Figure 8.-Mixed-flow tailpipe and offtake model test rig concept. 
Supersonic STOVL Application

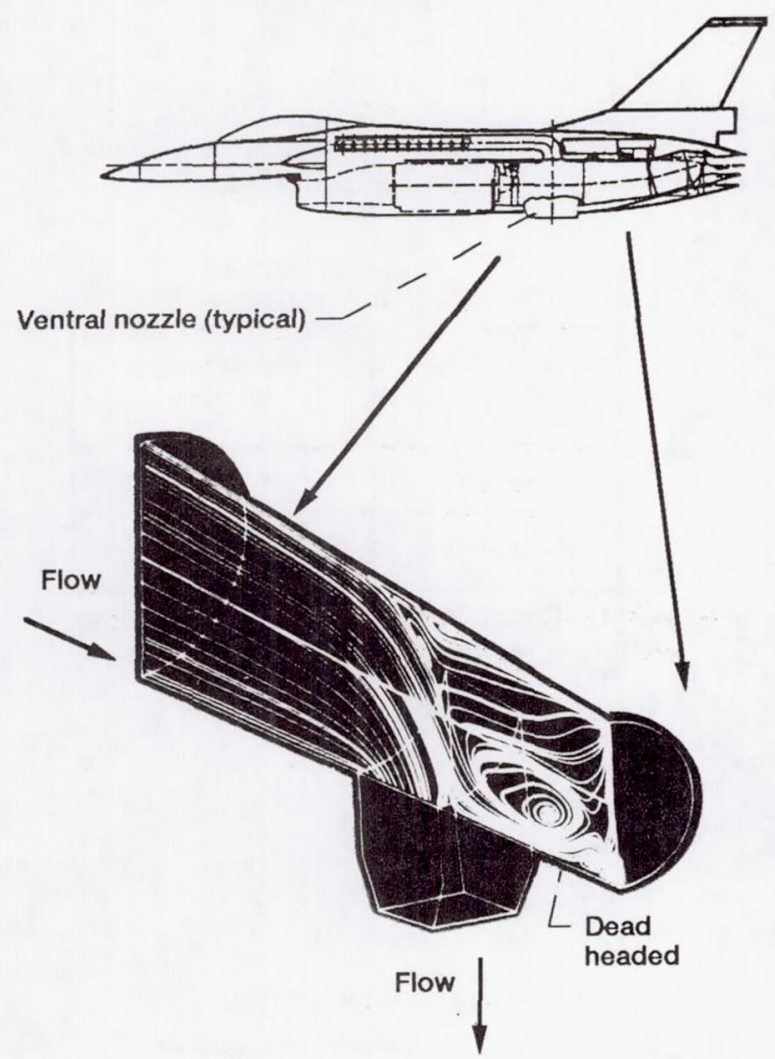

Plane of Symmetry Analysis

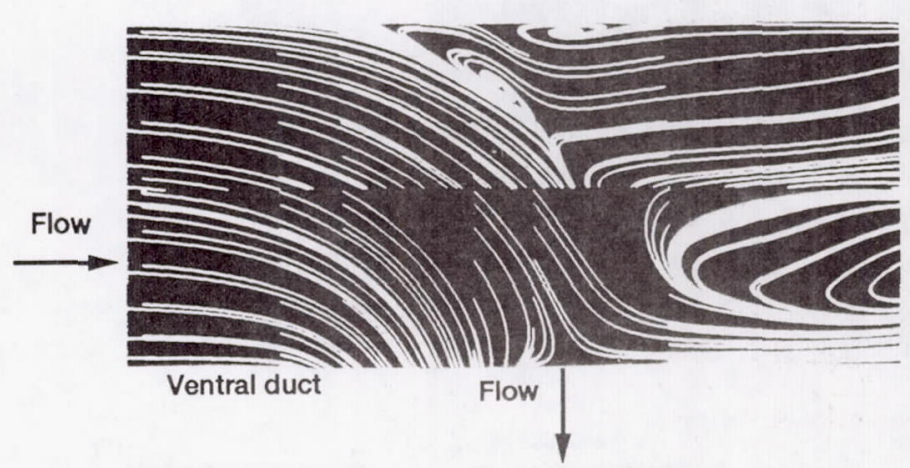

Experiment

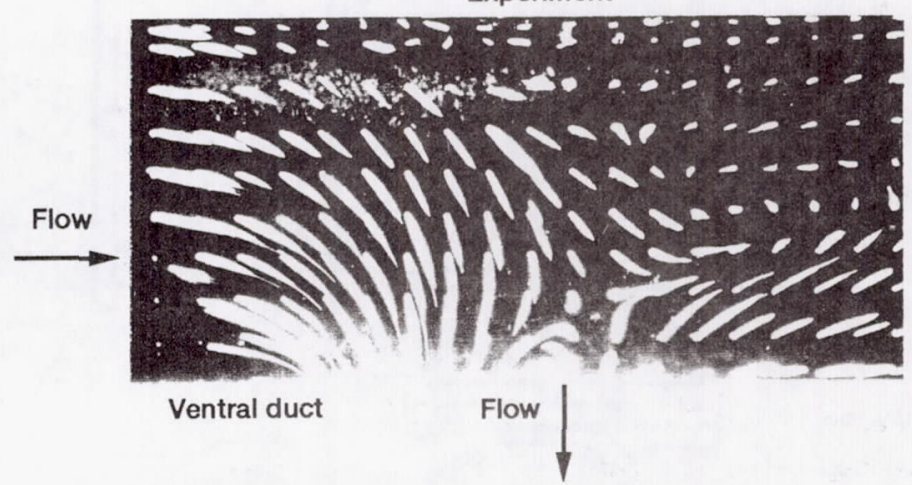

Figure 9.-Comparison of experimental and CFD analytical results. 

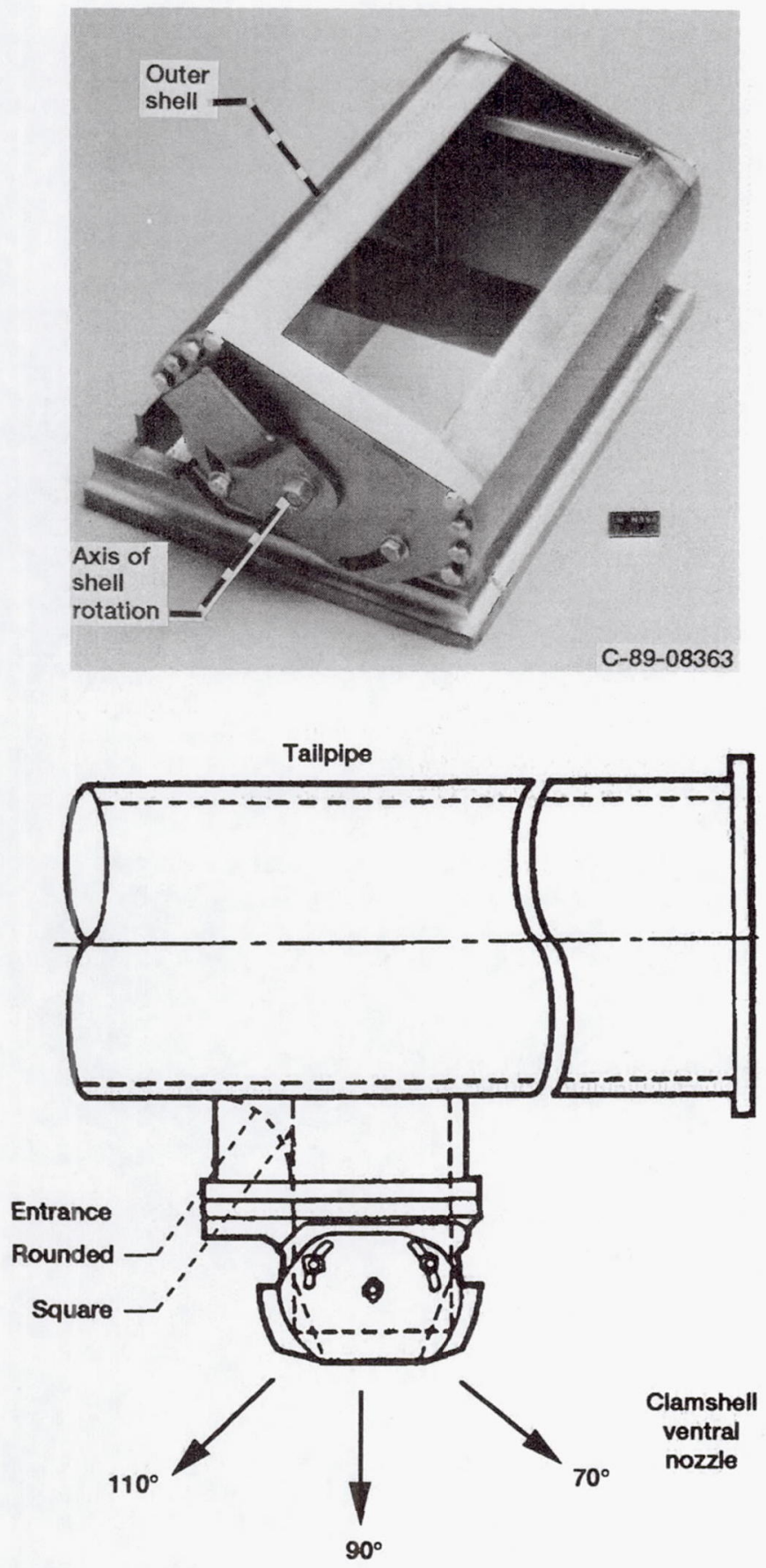

Figure 10.-Vectoring ventral nozzle concept.

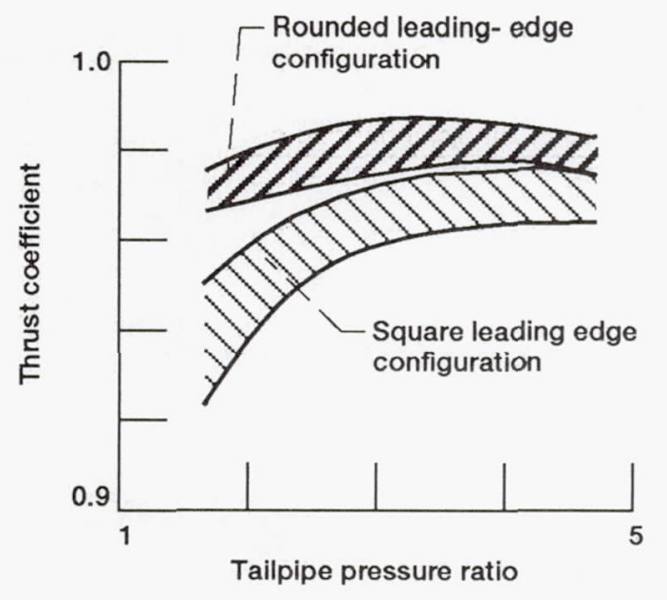

Effects of Ventral Entrance Geometry

\begin{tabular}{|c|c|}
\hline Leading edge & $\begin{array}{c}\text { Overturning, } \\
\text { degrees }\end{array}$ \\
\hline Square & 5 \\
\hline Rounded & 2 \\
\hline
\end{tabular}

Figure 11.-Results of tests with vectoring ventral nozzle.

$20^{\circ}$ forward $<$ vector $<45^{\circ}$ aft

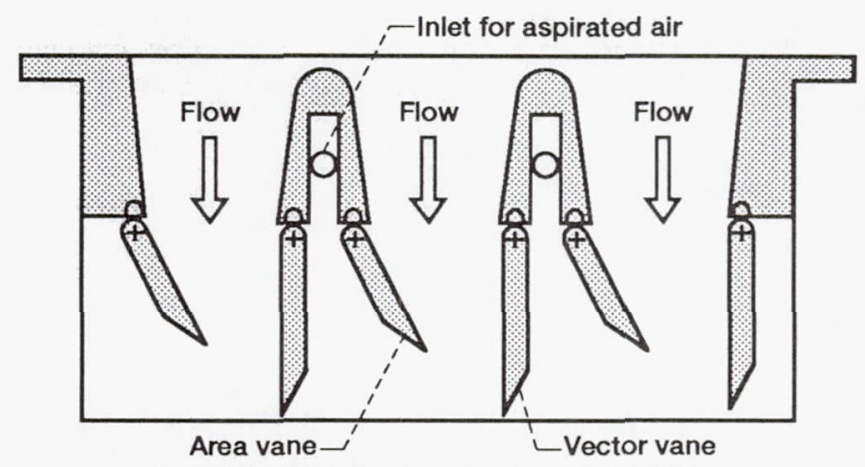

Figure12.-Details of a vaned ventral nozzle. 


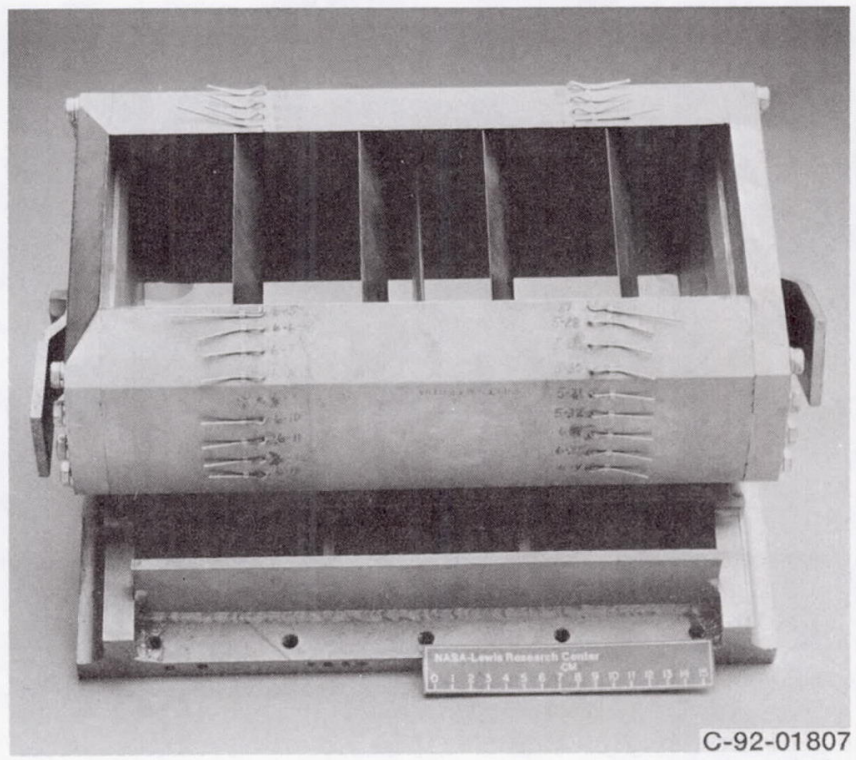

Figure 13.-Swivel nozzle with internal vanes for side force control.

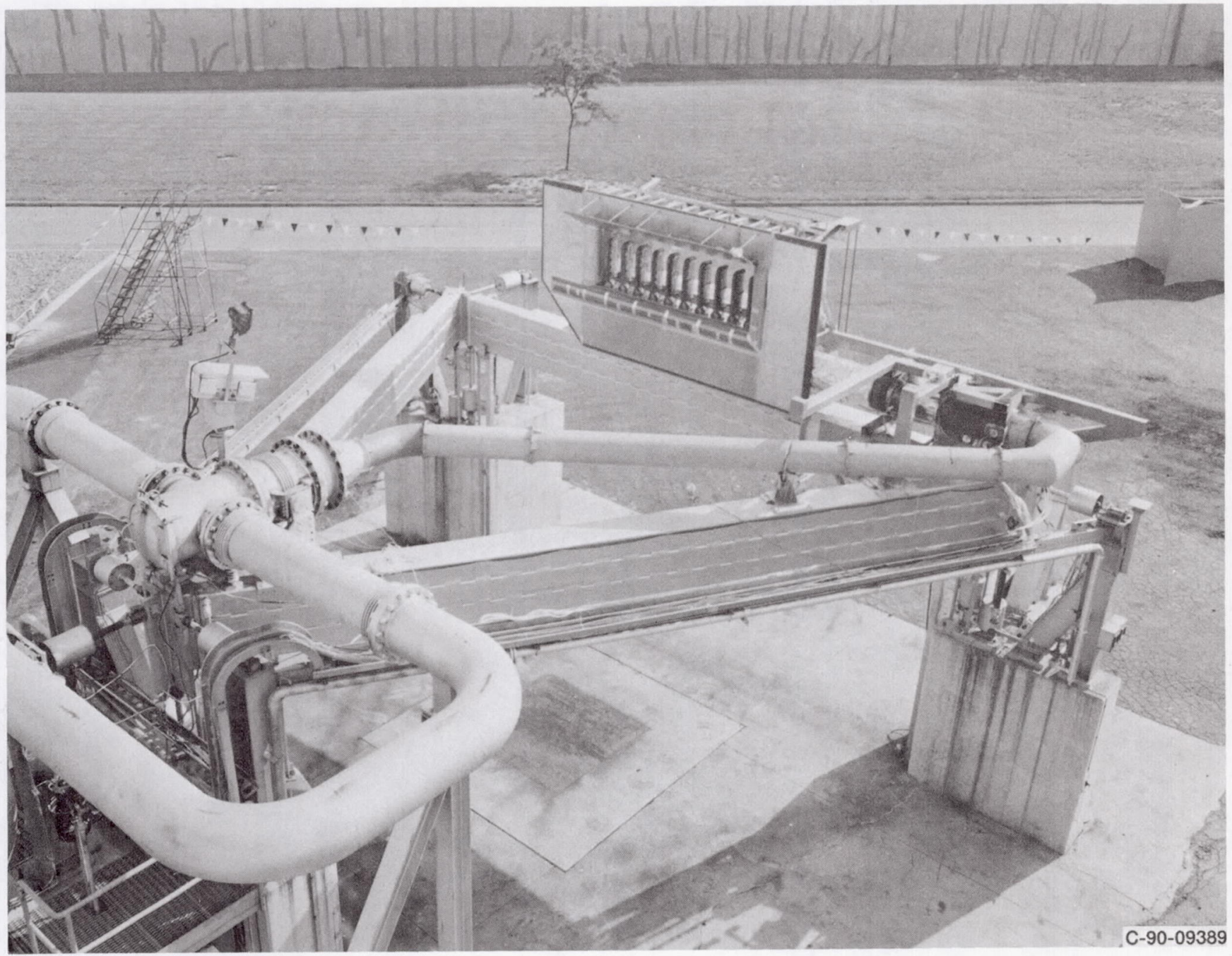

Figure 14.-Full-scale ejector augmentor installed at the Powered Lift Facility. 


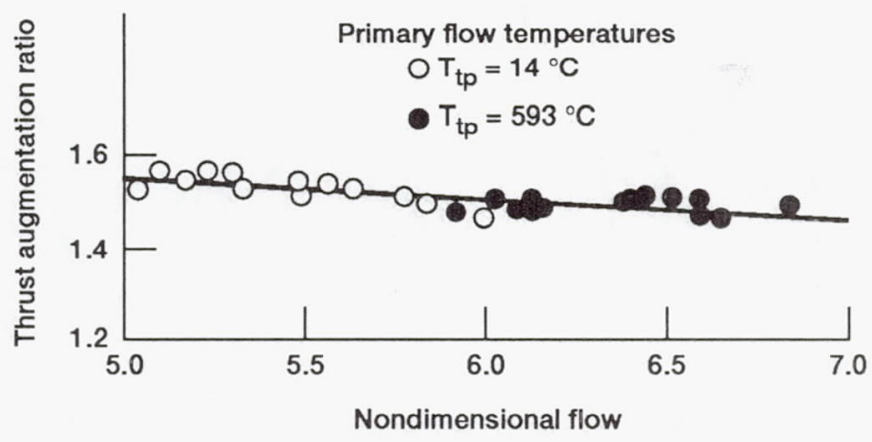

Figure 15.-Ejector performance as a function of nondimensional flow.

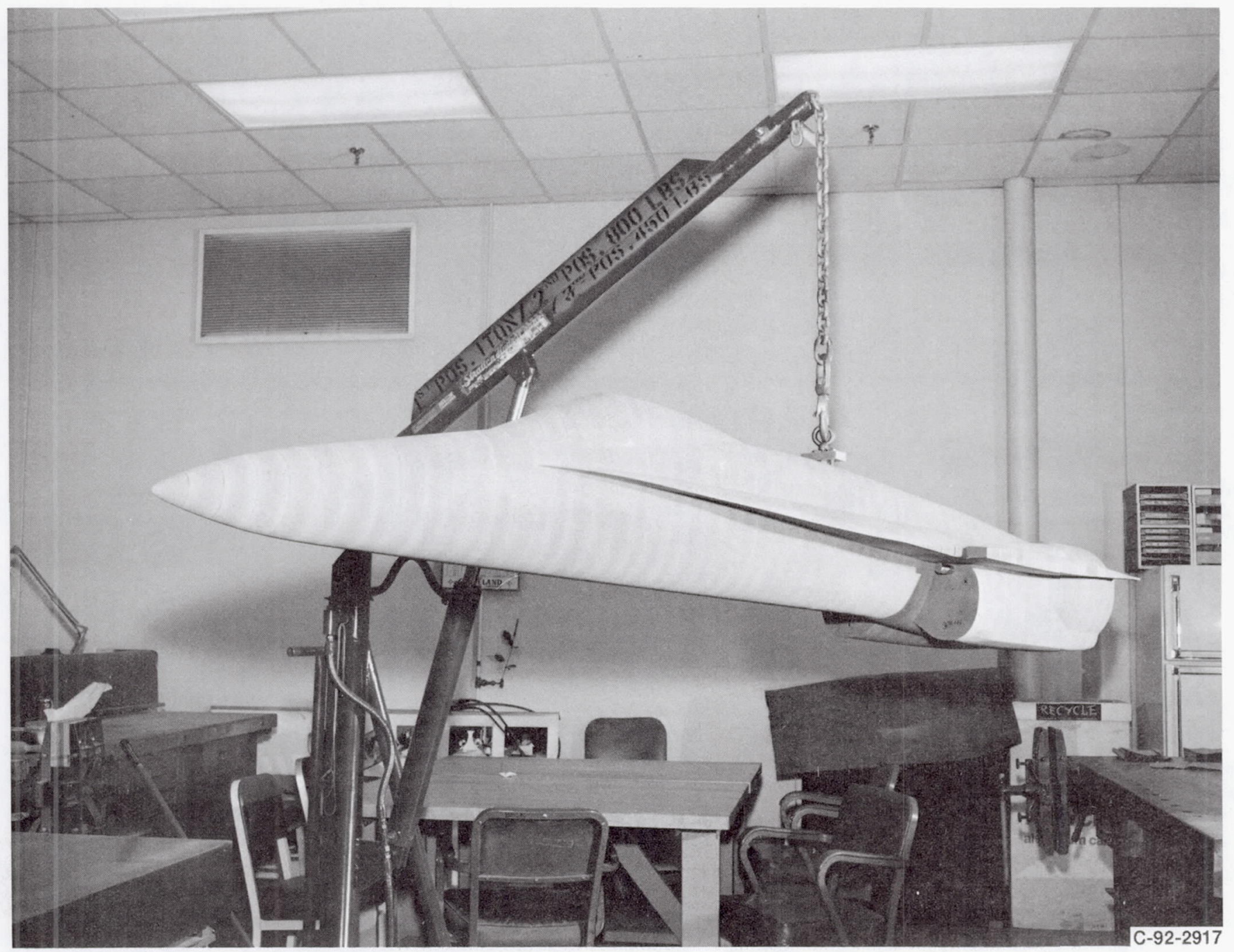

Figure 16.-F-18 aircraft 20-percent model. 


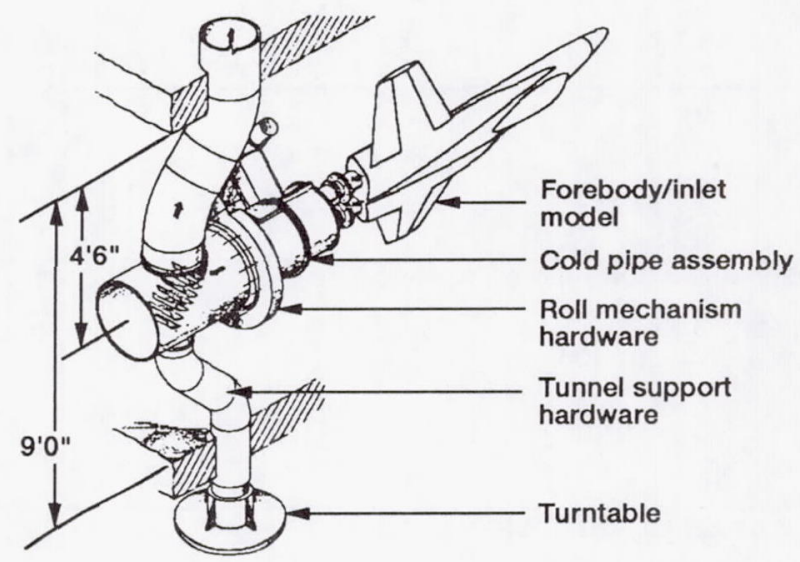

Figure 17.-F-18 model in $9 \times 15$ Low-Speed Wind Tunnel.

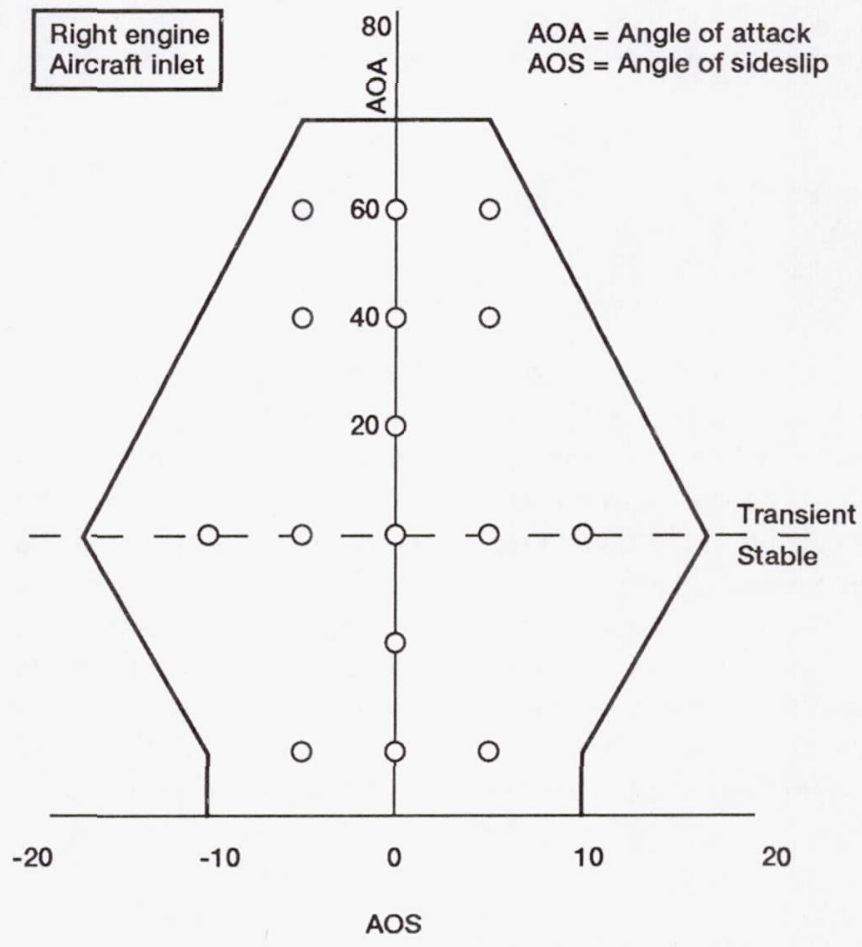

Figure 18.-Preliminary flight envelope for F-18 HARV Inlet Experiments Program. 
Public reporting burden for this collection of information is estimated to average 1 hour per response, including the time for reviewing instructions, searching existing data sources, gathering and maintaining the data needed, and completing and reviewing the collection of information. Send comments regarding this burden estimate or any other aspect of this collection of information, including suggestions for reducing this burden, to Washington Headquarters Services, Directorate for information Operations and Reports, 1215 Jefferson Davis Highway, Suite 1204, Arlington, VA 22202-4302, and to the Office of Management and Budget, Paperwork Reduction Project (0704-0188), Washington, DC 20503.

\section{\begin{tabular}{l|l|l}
\hline 1. AGENCY USE ONLY (Leave blank) & 2. REPORT DATE & 3. REPORT TYPE AND DATES COVERED
\end{tabular}}

\section{TITLE AND SUBTITLE}

October 1992

Technical Memorandum

Overview of High Performance Aircraft Propulsion Research

\section{FUNDING NUMBERS}

6. AUTHOR(S)

WU-505-68-32

Thomas J. Biesiadny

7. PERFORMING ORGANIZATION NAME(S) AND ADDRESS(ES)

8. PERFORMING ORGANIZATION REPORT NUMBER

National Aeronautics and Space Administration

Lewis Research Center

Cleveland, Ohio 44135-3191

E-7280

9. SPONSORING/MONITORING AGENCY NAMES(S) AND ADDRESS(ES)

10. SPONSORING/MONITORING AGENCY REPORT NUMBER

National Aeronautics and Space Administration

Washington, D.C. 20546-0001

NASA TM-105839

11. SUPPLEMENTARY NOTES

Prepared for the Aerotech '92 Conference, Anaheim, California, October 5-8, 1992. Thomas J. Biesiadny, NASA

Lewis Research Center. Responsible person, Thomas J. Biesiadny, (216) 433-3967.

12a. DISTRIBUTION/AVAILABILITY STATEMENT

12b. DISTRIBUTION CODE

Unclassified - Unlimited

Subject Category 07

\section{ABSTRACT (Maximum 200 words)}

This paper presents the overall scope of the NASA Lewis High Performance Aircraft Propulsion Research Program. High performance fighter aircraft of interest include supersonic flights with such capabilities as short take off and vertical landing (STOVL) and/or high maneuverability. The NASA Lewis effort involving STOVL propulsion systems is focused primarily on component-level experimental and analytical research. The high-maneuverability portion of this effort, called the High Alpha Technology Program (HATP), is part of a cooperative program among NASA's Lewis, Langley, Ames, and Dryden facilities. The overall objective of the NASA Inlet Experiments portion of the HATP, which NASA Lewis leads, is to develop and enhance inlet technology that will ensure high performance and stability of the propulsion system during aircraft maneuvers at high angles of attack. To accomplish this objective, both wind-tunnel and flight experiments are used to obtain steady-state and dynamic data, and computational fluid dynamics (CFD) codes are used for analyses. This overview of the High Performance Aircraft Propulsion Research Program includes a sampling of the results obtained thus far and plans for the future.

14. SUBJECT TERMS

Propulsion; STOVL; Aeronautical propulsion research; Controls

\begin{tabular}{l|c}
\hline $\begin{array}{l}\text { 17. SECURITY CLASSIFICATION } \\
\text { OF REPORT }\end{array}$ & $\begin{array}{c}\text { 18. SECURITY CLASSIFICATION } \\
\text { OF THIS PAGE } \\
\text { Unclassified }\end{array}$ \\
\begin{tabular}{c} 
Unclassified \\
\hline
\end{tabular}
\end{tabular}

NSN 7540-01-280-5500
19. SECURITY CLASSIFICATION OF ABSTRACT Unclassified
20. LIMITATION OF ABSTRACT 